\title{
Effect of controlled breeding on performance of beef cattle in Central Bushveld bioregion
}

\author{
S.M. Grobler ${ }^{1,2 \#}$, M.M. Scholtz ${ }^{2,3}$, F.W.C. Neser ${ }^{2}$ J.P.C. Greyling ${ }^{2} \&$ L. Morey ${ }^{4}$ \\ ${ }^{1}$ ARC-Animal Production Institute, Private Bag X05, Lynn East, 0039, South Africa; ${ }^{2}$ University of the Free State, PO \\ Box 339, Bloemfontein, 9301, South Africa; ${ }^{3}$ ARC-Animal Production Institute, Private Bag X2, Irene, 0062, South Africa; \\ ${ }^{4}$ ARC-Biometry, Central Office, PO Box 8783, Pretoria, 0001, South Africa
}

(Received 4 February 2019; Accepted 22 November 2019; First published online 1 January 2020)

Copyright resides with the authors in terms of the Creative Commons Attribution 4.0 South African Licence.
See: http://creativecommons.org/licenses/by/4.0/za
Condition of use: The user may copy, distribute, transmit and adapt the work, but must recognise the authors and the South African
Journal of Animal Science.

\begin{abstract}
In most extensive beef production systems in South Africa, calves are weaned at specific dates. This implies that cows that calve late in the season wean younger and lighter calves. In the current study, Bonsmara cows were mated naturally after synchronization over six years (2009 - 2014) in an extensive production system on natural veld in the Central Bushveld bioregion. Within the herd, $50 \%$ of cows were synchronized prior to the commencement of the summer breeding season and they were mated naturally for 90 days. The results indicated that calving rate did not differ significantly between cows that were synchronized and non- synchronized. However, there was a significant difference between years in calving rate. Oestrous synchronization prior to natural breeding influenced the average days to conception. The difference in percentage of cows that calved within 293 days of the onset of the breeding season between those that were oestrous synchronized and non-synchronized was $15 \%$ in favour of the synchronized cows. Although calves from synchronized cows achieved higher average weaning weights, the cost implications of synchronization offset the benefit of higher calf weights.
\end{abstract}

Keywords: calving rate, oestrous synchronization, natural breeding

${ }^{\#}$ Corresponding author: mgrobler@arc.agric.za

\section{Introduction}

According to the Department of Agriculture, Forestry and Fisheries (DAFF) in South Africa, livestock production is the only viable agricultural activity in a large part of the country, with approximately $80 \%$ of South African agricultural land being suitable only for extensive grazing (DAFF, 2012). The extensive grazing of beef cattle in these areas is the most practical method of production. Previous local studies concentrated on aspects that affected herd efficiency, including calving rate (Lademann \& Schoeman, 1994), pre-weaning growth (Venter, 1977), supplementation of cows and calves (Lishman et al., 1984; Lademann \& Schoeman, 1994; De Waal et al., 1996), and crossbreeding (Mentz, 1977; Meaker, 1984; Theunissen, 2011). However, none of the studies focused on the reproduction performance of beef cattle mated naturally after synchronization.

The Bureau for Food and Agricultural Policy (BFAP) estimates that South Africa's current annual average beef consumption of about 700000 tons is likely to increase by $25 \%$ by 2020 (De Jong et al., 2013). If the large numbers of weaner calves that are imported annually from neighbouring countries are considered, South Africa is still a net importer of beef (Scholtz et al., 2008). However, owing to several factors, including environmental concerns, the national beef herd cannot realistically be increased, and therefore it is important to improve existing production efficiency in South Africa (De Jong et al., 2013). The local quoted calving rate of $62 \%$ (Scholtz et al., 2008) in the commercial beef sector must be improved. In most of South Africa's extensive beef production systems, calves are weaned on a specific date. This management system implies that cows that calve late in the calving season wean younger and lighter calves, compared with cows that calve earlier in the season, since older calves have higher bodyweight gain from birth to weaning.

The aim of the study was to evaluate the effect of oestrous synchronization, followed by natural breeding, on calving rate and the distribution of calvings in the calving season. This was done to establish 
whether oestrous synchronization could lead to an increase in the total weight of calves that are weaned from a limited calving season. This could probably be done by decreasing the days to calving, leading to higher weaning weight from calves that are born early in the season, and increasing the number of calves that are born in a limited calving season.

\section{Materials and Methods}

The study was conducted from 2009 to 2014 at Roodeplaat Experimental Farm of the Agricultural Research Council Animal Production Unit (ARC-AP) (25 34'11.27'S; $28^{\circ} 22^{\prime} 05.36^{\prime \prime}$ ) on 900 ha of natural rangeland. The vegetation in the area has been described as Savanna (Rutherford \& Westfall, 1994), Sourish Mixed Bushveld (veld type 19) (Acocks, 1988), Clay Thorn Bushveld (Low \& Rebelo, 1996) and Marikana Thornveld (Mucina \& Rutherford, 2006) in the Savanna Biome, Central Bushveld Bioregion. During the study period, the mean annual rainfall was $858 \mathrm{~mm}$, and ranged from $664 \mathrm{~mm}$ to $1325 \mathrm{~mm}$. The mean daily minimum/maximum temperatures ranged from $16{ }^{\circ} \mathrm{C}$ (minimum) to $32{ }^{\circ} \mathrm{C}$ (maximum) in February (summer) and from $1{ }^{\circ} \mathrm{C}$ to $23^{\circ} \mathrm{C}$ in July (winter). The stocking rate, as determined by seasonal veld analysis of seven hectares per livestock unit (ha/LSU), was strictly adhered to with no changes in stocking rate over the study period. The animals were moved from one camp to another according to the established stocking rate, camp size and group size.

The study began in 2009 with 92 multiparous Bonsmara cows. The cows were divided into four equal groups ( $n=23 / g r o u p$ in 2009). Cows were allocated to the four groups, taking into account age, parity, and weight to ensure that all four groups were initially of the same age, parity and weight structure. In each of the four groups, approximately half the cows were oestrous synchronized prior to breeding, and the other half served as the control. The same cows were synchronized each year. Heifers that were calving for the first time were excluded from the trial, but second-calf cows were introduced into the groups each year. The four identical groups were subjected to the same management system and synchronization protocol because the study formed part of a bigger research project.

The breeding season lasted from early in January to March every year, and the calving season was from October until the end of December. Synchronization was done at the onset of the breeding season in the first week of January of each year $(2009$ - 2014). The animals that were selected for oestrous synchronization were treated with subcutaneous Crestar (Crestar ${ }^{\circledR}$, Intervet SA Ltd, Isando, RSA) implants in the right ear at the beginning of the summer breeding season (2009 - 2012) and a CIDR B (CIDR®, Pfizer Laboratory (Pty) Ltd, Sandton, RSA) intravaginal device (2013 - 2014) because Crestar was not available. The Crestar ear implant contained $3 \mathrm{mg}$ progestagen norgestomet (17a-acetoxyl-IIß-methyl-19-nor-pregn-4ene-3, 20-dione) (Crestar, Intervet SA Ltd, Isando, RSA), and was inserted subcutaneously at the outer edge of the right ear. Each application was followed immediately with an intramuscular $2 \mathrm{ml}$ Crestar injection (Crestar ${ }^{\circledR}$, Intervet SA Ltd, Isando, RSA) containing $3 \mathrm{mg}$ norgestomet and $5 \mathrm{mg}$ oestradiol valerate. The day of implant insertion was regarded as day 0 of treatment. The implants were removed on day 10 when the cows were injected intramuscularly with 300 - 400 IU Folligon containing pregnant mare serum gonadotropin (PMSG) before breeding commenced approximately 56 hours later (Crestar ${ }^{\circledR}$, Intervet SA Ltd, Isando, RSA). If the implant was lost before it was to be removed on day 10, the cow stayed physically in her group, but was removed from the trial for that breeding season. Implants that were lost over the trial period varied between two and three implants per year. The CIDR intravaginal device, a silicone coated nylon insert infused with $1.9 \mathrm{~g}$ progesterone, was inserted with an applicator into the anterior vagina. Each insertion was followed immediately by an intramuscular administration of a $1 \mathrm{mg}$ oestradiol benzoate (Ciderol) injection (Ciderol ${ }^{\circledR}$, Pfizer Laboratory (Pty) Ltd, Sandton, RSA). The day of device insertion was regarded as day 0 of treatment. The devices were removed on day 12 before breeding began 48 hours later. No CIDR devices were lost before removal on day 12.

Although the differences in synchronization methods were not analysed, because the same methods were used in the same year(s), differences in the efficacy of the methods would be negligible. In addition, the two methods worked on the same principle, namely keep the animal off heat with progestogens and then remove the implant (Crestar) or the device (CIDR) and allow the resultant flushing effect of oestrogen and luteinizing hormone (LH) to cause ovulation (Snyman, 2019).

One fertility-tested breeding bull was used in each group (2009 - 2011) for 90 days after the beginning of the breeding season. All breeding bulls were three years old at the onset of the project in 2009. According to Deutscher (1991), the number of cows serviced per bull can be between 5 and 20 in a 24-hour period. Therefore, two bulls were included in each group from 2012 to 2014, owing to the increase in cow numbers, because no cows were culled from 2012 onwards. Although bulls were not included as a random factor, the bulls were rotated among the groups every year. From 2012, two bulls that were paired in each group were rotated together to the next group. Herd management practices (e.g. dipping, vaccination) were standardized for all groups. The calving rate and calving interval distribution were recorded. Cows were managed 
extensively with commercial summer and winter licks being available. Calves were weaned at an average age of seven months. From 2012 onwards, body condition score (BCS) was assessed when animals were weighed. The effect on productivity of cows being synchronized or non-synchronized was studied over the six-year period (2009 - 2014).

The data of the two herds were combined after the variances had been tested for comparable magnitude using Levene's test (John \& Quenouille, 1977). A 2 × 2 factorial analysis of variance (ANOVA) was performed, the factors being two herds (herd 1 and herd 2) and two oestrous synchronization treatments (synchronized and non-synchronized) (Snedecor \& Cochran, 1967). The repeated measurements over the six years were included as a sub-plot factor (Little \& Hills, 1972). In addition, analysis of covariance was performed on variables (days to calving, cow weight at calving) using cow age as covariate for each year separately. Shapiro-Wilk's test was performed on the standardized residuals to test for deviations from normality (Shapiro \& Wilk, 1965). Where significant deviation from normality was due to skewness, outliers were removed (Glass et al., 1972). Student's t-test least significant difference (LSD) was calculated at 5\% significance level to compare means of significant source effects. All data analyses were performed using SAS version 9.3 statistical software (SAS Institute, Inc., Cary, North Carolina, USA).

\section{Results and Discussion}

Over the six-year period, no significant, difference $(P=0.52)$ was recorded for the calving rates of cows that were synchronized at the beginning of the breeding season and cows that were bred naturally without synchronization (Table 1). However, there was a significant difference $(P=0.04)$ between years in calving rate, indicating that factors such as climate and weather patterns may have had an effect on reproduction. Calving rate was highest in the first calving season (2009) and lowest in the second (2010).

Table 1 Mean calving rate of cows mated naturally with and without oestrous synchronization \pm SD over a six-year period

\begin{tabular}{|c|c|c|c|}
\hline \multicolumn{4}{|c|}{ Mean calving rate } \\
\hline Year & Synchronized cows & Non-synchronized cows & Mean $^{\Delta}$ \\
\hline $2009^{\star}$ & $93.0 \pm 8.8^{\mathrm{a}}$ & $86.3 \pm 4.3^{\mathrm{ab}}$ & $89.6 \pm 7.4^{\mathrm{a}}$ \\
\hline $2010^{*}$ & $61.5 \pm 8.4^{c}$ & $60.3 \pm 7.9^{c}$ & $60.9 \pm 7.6^{b}$ \\
\hline $2011^{*}$ & $77.5 \pm 17.1^{\mathrm{abc}}$ & $68.7 \pm 16.5^{\mathrm{bc}}$ & $73.1 \pm 16.2^{b}$ \\
\hline $2012^{*}$ & $62.2 \pm 19.6^{\mathrm{c}}$ & $80.0 \pm 20.0^{\mathrm{ab}}$ & $71.1 \pm 20.6^{b}$ \\
\hline $2013^{\star \star}$ & $65.7 \pm 18.5^{c}$ & $72.4 \pm 9.1^{\mathrm{abc}}$ & $69.1 \pm 14.0^{b}$ \\
\hline $2014^{\star *}$ & $62.0 \pm 15.6^{c}$ & $61.0 \pm 10.8^{c}$ & $61.5 \pm 12.4^{b}$ \\
\hline Mean & $70.3 \pm 17.9$ & $71.4 \pm 14.7$ & \\
\hline $\begin{array}{l}\Delta^{a, b} \text { Mean } \\
\operatorname{LSD}_{(p=0.05)} \\
\operatorname{LSD}_{(\mathrm{p}=0.05)} \\
{ }^{*} \text { Oestrous } \\
{ }^{* *} \text { Oestrous }\end{array}$ & $\begin{array}{l}\text { ts in this column diffe } \\
\text { Crestar }{ }^{\circledR} \\
\text { CIDR }{ }^{\circ}\end{array}$ & ficantly $(P \leq 0.05)$ & \\
\hline
\end{tabular}

Differences in rainfall and ambient temperature over the period could have contributed to the highest calving rate in 2009 and the lower calving rates in 2010 and 2014 . Table 2 indicates that the annual rainfall was exceptionally high in 2009 when the highest calving rate occurred.

Table 2 Average annual rainfall in the Central Bushveld Bioregion during the study period

\begin{tabular}{lccccccc}
\hline Year & 2009 & 2010 & 2011 & 2012 & 2013 & 2014 & Mean \\
\hline Rainfall (mm) & 1324 & 772 & 1025 & 676 & 685 & 664 & 858 \\
\hline
\end{tabular}


The monthly minimum and maximum temperatures are shown in Table 3 . The mean daily minimum/maximum temperatures ranged from $16{ }^{\circ} \mathrm{C}$ to $32{ }^{\circ} \mathrm{C}$ in February (summer) and $1{ }^{\circ} \mathrm{C}$ to $23{ }^{\circ} \mathrm{C}$ in July (winter). The years 2009 and 2011 were the only two in which the maximum temperatures for the warmest month (February) were below $30^{\circ} \mathrm{C}$ (Table 3).

Table 3 Monthly minimum and maximum temperatures $\left({ }^{\circ} \mathrm{C}\right)$ over the six-year project at Roodeplaat, Pretoria

\begin{tabular}{lllllllllllll}
\hline Year & Jan & Feb & Mar & Apr & May & Jun & Jul & Aug & Sep & Oct & Nov & Dec \\
\hline 2009 & $18 / 30$ & $16 / 29$ & $14 / 28$ & $9 / 28$ & $6 / 22$ & $4 / 22$ & $1 / 20$ & $4 / 23$ & $9 / 29$ & $14 / 29$ & $14 / 28$ & $16 / 29$ \\
2010 & $18 / 29$ & $16 / 31$ & $15 / 30$ & $13 / 24$ & $8 / 24$ & $2 / 21$ & $4 / 21$ & $4 / 25$ & $9 / 30$ & $14 / 32$ & $16 / 30$ & $16 / 29$ \\
2011 & $17 / 28$ & $16 / 29$ & $15 / 30$ & $12 / 25$ & $6 / 24$ & $1 / 21$ & $1 / 20$ & $4 / 24$ & $8 / 29$ & $12 / 29$ & $14 / 30$ & $17 / 29$ \\
2012 & $17 / 31$ & $17 / 31$ & $14 / 30$ & $9 / 26$ & $6 / 26$ & $2 / 22$ & $3 / 23$ & $5 / 25$ & $9 / 26$ & $12 / 28$ & $14 / 29$ & $16 / 29$ \\
2013 & $17 / 31$ & $16 / 32$ & $14 / 30$ & $9 / 26$ & $5 / 25$ & $2 / 23$ & $3 / 22$ & $4 / 24$ & $11 / 29$ & $12 / 29$ & $15 / 30$ & $16 / 28$ \\
2014 & $17 / 31$ & $17 / 30$ & $17 / 24$ & $10 / 25$ & $6 / 25$ & $2 / 22$ & $2 / 21$ & $5 / 23$ & $10 / 29$ & $12 / 29$ & $15 / 27$ & $17 / 28$ \\
\hline
\end{tabular}

Source: Climatology Staff, 2015

In extensively managed cows, oestrus can be delayed, pregnancy rates decreased, and calf bodyweight at weaning reduced under drought conditions (Bedell \& Ganskopp, 1980). However, Mulliniks et al. (2012) found that yearly rainfall did not account for variation in days to first postpartum ovulation, pregnancy rates, and days to calving, meaning that rainfall distribution, temperature, humidity and other climatic factors may play an important role in annual cow productivity. However, rainfall before and during the breeding season may have had an effect on forage quality, forage quantity, and cow comfort. This may be the reason for the high calving rate in 2009 and low calving rates in 2010 and 2014.

The mean calving rate of all cows, synchronized and non-synchronized (Table 1), varied between $61 \%$ and $90 \%$, which is in line with results from Patterson et al. (2005), who reported calving rates of between $60 \%$ and $94 \%$ for various experimental herds, while Deutscher (1991) reported pregnancy rates of $60 \%$ to $80 \%$ after synchronization using natural service by bulls. The calving rates for the project in 2010 (61\%) and $2014(62 \%)$ were close to the national calving rate of $62 \%$ in the commercial beef sector of South Africa (Grobler et al., 2013), whereas those for 2009 (90\%), 2011(73\%), 2012 (71\%), and 2013 (69\%) were above the national average.

'Days to calving' was calculated as the number of days from the time that the cows were joined with the bull to calving. Because the oestrous cycle is approximately 21 days, the calvings were grouped into five categories. In a study by Van Graan et al. (2004), it was found that the gestation period of Bonsmara cows is $286 \pm 7$ days. Therefore, it was assumed that cows that conceived from the synchronized oestrous breeding would calve within 293 days. In other words, all cows that became pregnant in the first week after the bulls were added to the groups, would be included in this category.

Days 294 - 306 accounted for the rest of the first 21-day oestrous cycle within the breeding season. This related to all cows that became pregnant in the second and third weeks after the bulls were added. Days 307 - 327 accounted for the second oestrous cycle, indicating cows that became pregnant between four and six weeks of the bulls being added. Days 328 - 348 represented the third oestrous cycle. The days after 348 days represented the cows that calved late in the breeding season after the third oestrous cycle. Figure 1 indicates the average days to calving for cows that were synchronized or non-synchronized over the six-year project. 


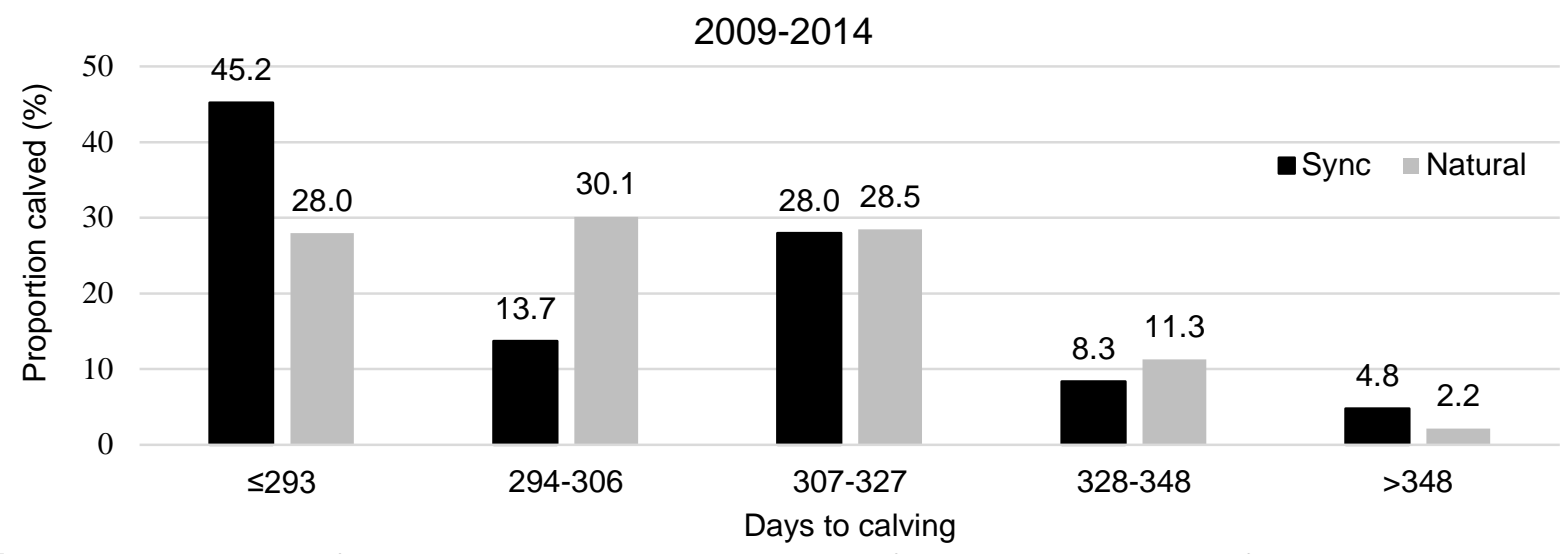

Figure 1 Percentage of cows calving at various intervals of the breeding season for synchronized and nonsynchronized multiparous Bonsmara cows over six-year period (2009 - 2014)

The number of days to calving from 2009 to 2014 (Figure 1) indicated that a greater number of synchronized cows calved earlier in the calving season. These cows had a longer recovery period and reduced lactation stress (Odhiambo et al., 2009). Having cows calve early in the season results in a calf crop that can be weaned earlier or at a heavier bodyweight. Earlier weaning may lead to increased body energy reserves for cows at calving, and minimize the effects of a negative energy balance in the postpartum interval and subsequent breeding performance. In a study by Holm (2006), in which beef heifers were inseminated after synchronization, it was concluded that synchronization might lead to an increase in the total weight of calves that were weaned from a limited calving season, probably by decreasing the days to calving, and also by increasing the number of calves that were born. Different seasonal patterns and mortality rates of calves (caused by disease and climate) could contribute to an increase in the total weight of calves that were weaned if the concentrated calving season was synchronized with the 'good' season (that is conducive to cow and calf health). However, a negative effect on calf health and weaning potential could result if the calving season was synchronized with the 'poor' season (seasonal diseases, excessive heat, cold, dry matter availability), which is detrimental to cow and calf health.

The annual days to calving over the six-year project (2009 - 2014) indicated that a higher percentage of synchronized cows calved in the first week of the breeding season (Table 4). In a study by Nath et al. (2004) nine out of ten postpartum cows in anoestrus exhibited oestrus after Crestar treatment. They also found that five out of nine cows that ovulated after induced oestrus conceived. A low conception rate of $55.6 \%$ was recorded, but only cows in postpartum anoestrus were used. Nath et al. (2004) also reported a fairly low conception rate of $56.2 \%$ in postpartum crossbred cows following a combined hormonal treatment of progesterone and PMSG.

Table 4 Number of cows (\%) calving at various intervals of the breeding season for the six-year project period, including synchronized and non-synchronized multiparous cows

\begin{tabular}{lcccccc}
\hline & \multicolumn{2}{c}{ Synchronized cows } & \multicolumn{2}{c}{ Non-synchronized cows } & \multicolumn{2}{c}{ Test for association } \\
\hline Days to calving & $\leq 293$ & $>293$ & $\leq 293$ & $>293$ & $X^{2}($ df) value; P-value & Odds ratio \\
\hline 2009 & $15(45 \%)$ & $18(55 \%)$ & $9(29 \%)$ & $22(71 \%)$ & $X^{2}(1)=1.84 ; P=0.175$ & OR $=2.04$ \\
2010 & $13(65 \%)$ & $7(35 \%)$ & $10(38 \%)$ & $16(62 \%)$ & $X^{2}(1)=3.18 ; P=0.074$ & OR $=2.97$ \\
2011 & $10(33 \%)$ & $20(67 \%)$ & $7(24 \%)$ & $22(76 \%)$ & $X^{2}(1)=0.61 ; P=0.436$ & OR $=1.57$ \\
2012 & $6(25 \%)$ & $18(75 \%)$ & $7(22 \%)$ & $25(78 \%)$ & $X^{2}(1)=0.08 ; P=0.784$ & OR $=1.19$ \\
2013 & $11(39 \%)$ & $17(61 \%)$ & $7(21 \%)$ & $27(79 \%)$ & $X^{2}(1)=2.61 ; P=0.107$ & OR $=2.50$ \\
2014 & $21(64 \%)$ & $12(36 \%)$ & $12(35 \%)$ & $22(65 \%)$ & $X^{2}(1)=5.38 ; P=0.020$ & OR $=3.21$ \\
\hline Total & $76(45 \%)$ & $92(55 \%)$ & $52(28 \%)$ & $134(72 \%)$ & $X^{2}(1)=11.42 ; P<0.001$ & OR $=2.13$ \\
\hline
\end{tabular}


Lamb et al. (2007) conducted a study to determine whether insertion of the CIDR device seven days prior to the breeding season and removing it on the day the bulls were introduced to the cowherd would alter overall pregnancy rates, average days to conception, and subsequent calving distribution. The results are in line with those from the current study. In the study by Lamb et al. (2007), the pregnancy rates ranged from $59 \%$ to $99 \%$, while the pregnancy rates in the current study varied between $60 \%$ and $93 \%$. Similar to the results in the current study, no difference in calving rate was recorded between the CIDR and nonsynchronized cows in the study by Lamb et al. (2007). However, in the oestrous-synchronized cows, the average days to calving was shorter $(P \leq 0.05)$. The number of oestrous-synchronized cows that conceived within the first 10 days of the breeding season was $8 \%$ higher than for the non-synchronized cows. In the current study, the difference between synchronized cows and non-synchronized cows that calved within 293 days of breeding was $16 \%$ higher for synchronized cows in 2009, 27\% higher in 2010, $9 \%$ higher in 2011 , $3 \%$ higher in 2012, 18\% higher in 2013 and 29\% higher in 2014 (Table 4). Over the six-year project period the odds were 2.13 times higher that a synchronised cow would calf within 293 days of breeding $(P<0.001)$.

According to Holm et al. (2008), the direct benefit of a synchronization protocol is related to the higher total weight of calves that can be weaned. This observation coincides with the current study's results, where the mean calf weaning weight varied between $214 \mathrm{~kg}$ and $186 \mathrm{~kg}$ for calves that were weaned from cows that were synchronized at breeding, and between $210 \mathrm{~kg}$ and $168 \mathrm{~kg}$ for calves that were weaned from cows that were not synchronized (Table 5).

Table 5 Mean calf weaning weight \pm SD $(\mathrm{kg})$ of calves conceived from cows mated naturally with or without oestrous synchronization over the six-year study

\begin{tabular}{|c|c|c|}
\hline & Calf weaning weight \pm SD from synchronized cows & Calf weaning weight \pm SD from non-synchronized cows \\
\hline 2009 & $206.0 \pm 28.4^{\mathrm{a}}$ & $210.0 \pm 19.7^{\mathrm{a}}$ \\
\hline 2010 & $214.6 \pm 21.9^{\mathrm{a}}$ & $202.4 \pm 27.8^{\mathrm{a}}$ \\
\hline 2011 & $202.6 \pm 24.9^{\mathrm{a}}$ & $205.1 \pm 17.2^{\mathrm{a}}$ \\
\hline 2012 & $179.0 \pm 25.8^{\mathrm{bc}}$ & $178.7 \pm 28.6^{\mathrm{bc}}$ \\
\hline 2013 & $179.3 \pm 28.3^{\mathrm{bc}}$ & $173.9 \pm 21.8^{\mathrm{bc}}$ \\
\hline 2014 & $186.1 \pm 27.8^{\mathrm{b}}$ & $168.0 \pm 30.7^{c}$ \\
\hline Mean & $194.5 \pm 29.2^{\mathrm{A}}$ & $188.0 \pm 30.0^{\mathrm{B}}$ \\
\hline
\end{tabular}

On average, the synchronized cows weaned calves that were $6.5 \mathrm{~kg}$ heavier $(P \leq 0.05)$ in the current study (2009 - 2014). At an assumed weaner price of R35/kg live weight (RPO, 2017), the difference may translate to R227.50 more per calf. The direct costs of the synchronization products, excluding veterinary and labour costs, currently varies between R50.00 (15\%, VAT included) for a single cloprostenol sodium injection and R165.00 (15\%, VAT included) for a progesterone infused intravaginal device, including $1 \mathrm{mg} / \mathrm{ml}$ oestradiol benzoate injection. Thus, the direct benefit per cow would be between R62.50 and R177.50. However, the calving rate of $71 \%$ for both synchronized and non-synchronized cows must be taken into account because not all treated cows raised a calf. Therefore, it is not economically viable to synchronize multiparous fertile cows, which are mated naturally and managed under extensive conditions. The financial benefit of synchronization would depend on the cost, weighed against weaning weight, weaning percentage, and the price per kilogram of weaned calves.

Over the study period, the mean cow age of groups changed, owing to mortalities and heifers calving to become cows. Therefore, cow weight was corrected for cow age by using cow age as a covariate in the weight analysis. When the mean bodyweight of cows at calving for synchronized and non-synchronized cows considered, the cows that were synchronized recorded an average weight that was slightly higher than that of the non-synchronized cows in four of the six years. This is an indication that synchronization may have a positive effect on cow weight at calving over time, because synchronized cows calved earlier in the season and hence had a longer recovery period and more time to regain condition, compared with those that were not synchronized. 
Body condition score was measured at breeding from 2012 onwards. Mean BCS did not differ significantly $(P \leq 0.05)$ between cows that were synchronized or non-synchronized.

\section{Conclusions}

The results from this study showed that calving rate did not differ significantly between cows that were synchronized and non-synchronized, followed by natural breeding. These results are consistent with similar studies (Hanon, 1995; Lamb et al., 2007). The average weaning weight of calves from the synchronized cows was significantly heavier $(6.5 \mathrm{~kg})$ than for those from non-synchronized cows over the six-year period. Oestrous synchronization prior to natural breeding influenced the average days to conception. This finding is consistent with other reports and may provide a practical way to decrease the length of the breeding season and increase the cow recovery period before the next breeding season to improve subsequent reproductive performance (Lamb et al., 2007; Odhiambo et al., 2009; Grobler et al., 2013). In the current study, there was no clear cost benefit from synchronizing fertile productive cows, followed by natural breeding under extensively managed conditions.

\section{Acknowledgements}

This work is based on research that was supported in part by Red Meat Research and Development South Africa and the National Research Foundation of South Africa (NRF), under grant UID 83933. The grantholder acknowledges that opinions, findings, conclusions and recommendations expressed in any publication generated by NRF-supported research are those of the authors and that the NRF accepts no liability whatsoever in this regard.

\section{Authors' Contributions}

The study was conceived by SMG, based on the PhD study of SMG, which was produced under the supervision of MMS, FWCN and JPCG. SMG oversaw the preparation of the data. LM did the analysis of the data. All authors evaluated the manuscript critically.

\section{Conflict of Interest Declaration}

The authors declare that they have no conflicts of interest with regard to this work.

\section{References}

Acocks, J.P.H., 1988. Veld types of South Africa, 3rd ed. Mem. Bot. Surv. S. Afr. 57, 1-146.

AgroClimatology Staff, 2015. ARC-ISCW Climate Information System. ARC-Institute for Soil, Climate and Water, Pretoria.

Bedell, T.E. \& Ganskopp, D.C., 1980. Rangelands in dry years: Drought effect on range, cattle, management. Pacific Northwest Extension Publication. Oregon State Univ. Cooperative Extension Serv., Corvallis, OR.

DAFF, 2012. Abstract of Agricultural Statistics 2012. Directorate Statistics and Economic Analysis, Department of Agriculture, Forestry and Fisheries. Resource Centre, Directorate: Communication Services, Pretoria, South Africa.

De Jong, J. \& Phillips, L., 2013. South Africa's beef industry: What does the future hold? Farmer's Weekly, 31 August 2013.

De Waal, H.O., Randall, J.H. \& Koekemoer, G.J., 1996. The effects of phosphorus supplementation on body mass and reproduction of grazing beef cows supplemented with different levels of phosphorus at Armoedsvlakte. S. Afr. J. Anim. Sci. 26, 29-36.

Deutscher, G.H., 1991. G85-741 Estrous synchronization for beef cattle. In: Historical Materials from University of Bebraska-Lincoln Extension, Lincoln.

Glass, G.V., Peckham, P.D. \& Sanders, J.R., 1972. Consequences of failure to meet assumption underlying the fixed effects analyses of variance and covariance. Rev. Educ. Res. 42, 237-288.

Grobler, S.M., Scholtz, M.M., Schwalbach, L.M.J. \& Greyling, J.P.C., 2013. Effect of synchronisation on calving date following natural mating in beef cattle. Appl. Anim. Husb. Rural Dev. 6, 15-17. http://www. sasas.co.za/aahrd/.

Hanon, D.W., 1995. The use of oestradiol benzoate and progesterone to synchronise oestrus in dairy cattle. MVSc thesis, Massey University, New Zealand.

Holm, D.E., 2006. The economic effects of an oestrus synchronization protocol using prostaglandin and reproductive tract scoring in beef heifers in South Africa. PhD thesis, University of Pretoria, South Africa.

Holm, D.E., Thompson, P.N. \& Irons, P.C., 2008. The economic effects of an estrus synchronization protocol using prostaglandin in beef heifers. Theriogenology 70, 1507-1515.

John, J.A. \& Quenouille, M.H., 1977. Experiments: Design and analysis; Charles Griffin \& Co, London. Ch. 13, $232-248$.

Lademann, E.E. \& Schoeman, S.J., 1994. Factors influencing recalving rate in lactating beef cows in the sweet dry Bushveld of northern Transvaal. S. Afr. J. Anim. Sci. 24(1), 30-33.

Lamb, G.C., Larson, J.E. \& Dahlen, C.R., 2007. Estrous synchronization protocols for cows. Proc. ARSBC. 11-12 September 2007, Billings, Montana. pp. 99-114.

Lishman, A.W., Lyle, A.D., Smith, V.W. \& Botha, W.A., 1984. Conception rate of beef cows and growth of suckling calves as influenced by date of calving and supplementary feeding. S. Afr. J. Anim. Sci. 14(1), 10-19.

Little, M.L. \& Hills, F.J., 1972. Statistical methods in agricultural research. University of California, Davis, California, USA. 
Low, A.B. \& Rebelo, A.G., 1996. Vegetation of South Africa, Lesotho and Swaziland. Dept. Environmental Affairs and Tourism, Pretoria, South Africa.

Meaker, H.J., 1984. Effective extensive beef production as a prelude to feedlotting. S. Afr. J. Anim. Sci. 14(4), 158-163.

Mentz, A.H., 1977. Produksiepotensiaal van verskillende eerstekruising Afrikanerbeeste. MSc (Agric) thesis, University of Orange Free State, South Africa.

Mucina, L. \& Rutherford, M.C., 2006. The vegetation of South Africa, Lesotho and Swaziland. Strelitzia 19. South African National Biodiversity Institute, Pretoria, South Africa.

Mulliniks, J.T., Cox, S.H., Kemp, M.E., Endecott, R.L., Waterman, R.C., Van Leeuwen, D.M. \& Petersen, M.K., 2012. Relationship between body condition score at calving and reproductive performance in young postpartum cows grazing native range. J. Anim. Sci. 90(8), 2811-2817.

Nath, H.C., Dutta, D.J., Dutta, A. \& Biswas, R.K., 2004. Reproductive performances of Crestar and PMSG administered to postpartum anoestrus cows. Indian J. Anim. Res. 38(1), 50-52.

Odhiambo, J.F., Rhinehart, D.J., Helmondollar, R., Pritchard, J.Y., Osborne, P.I., Felton E.E. \& Dailey, R.A., 2009. Effect of weaning regimen on energy profiles and reproductive performance of beef cows. J. Anim. Sci. 87(7), 24282436.

Patterson, D.J., Wood, S.L. \& Randle, R.F., 2005. Procedures that support reproductive management of replacement beef heifers. Proc. ARSBC. 12-13 November 2005 A \& M University, Texas. pp. 1-22.

RMRD SA., 2012. Research and development plan for the large and small stock meat industries in South Africa, 20122013. http://www.rmrdsa.co.za/

RPO., 2017. ABSA weekly prices, July-December 2017. http://www.rpo.co.za/information-centre/absa/weekly-prices/

Rutherford, M.C. \& Westfall, R.H., 1994. Biomes of Southern Africa: An objective categorization. 2nd edition. Mem. Bot. Surv. S. Afr. 63,1-94.

Scholtz, M.M., Bester, J., Mamabolo, J.M. \& Ramsay, K.A., 2008. Results of the national cattle survey undertaken in South Africa, with emphasis on beef. Appl. Anim. Husb. Rural Dev. 1, 1-8.

Shapiro, S.S. \& Wilk, M.B., 1965. An analysis of variance test for normality (complete samples). Biometrika 52, $591-611$.

Snedecor, G.W. \& Cochran, W.G., 1967. Statistical methods. Sixth edition. The lowa State University Press, AMES, IOWA USA.

Snyman, M.G., 16 April 2019. Personal communication with Dr Thys Snyman, Specialist Veterinary Pharmacologist.

Theunissen, A., 2011. Characterization of breed additive and heterosis effects in beef cattle using experimental results. MSc (Agric) dissertation, University of the Free State, South Africa

Van Graan, A.C., Neser, F.W.C., Van der Westhuizen, J. \& Theron, H.E., 2004. Genetic and phenotypic parameter estimates of gestation length and birth weight in Bonsmara cattle. S. Afr. J. Anim. Sci. 34(2), 95-97.

Venter, H.A.W., 1977. Die invloed van voorspeense groei by sekere vleis-, dubbeldoel- en kruisrasse in die NoordTransvaalse Soetbosveld. DSc (Agric) thesis, University of Pretoria, South Africa. 